\title{
The use of interactive tables in promoting wellbeing in specific user groups
}

\author{
Alice Good ${ }^{1[0000-0002-1624-1218]}$ Omobolanle Omisade ${ }^{\text {[0000-0003-2730-0401] }}$ Claire \\ Ancient $^{3[0000-0002-8889-7670]}$ Elisavet Andrikopoulou ${ }^{4[0000-0002-4614-2907]}$ \\ ${ }^{1}$ School of Computing, University of Portsmouth, UK a lice.goodeport.ac.uk \\ ${ }^{2}$ School of Computing, University of Portsmouth, UK \\ omobolanle.omisade@port.ac.uk \\ ${ }^{3}$ Department of Digital Futures, University of Winchester, UK \\ claire.ancient@winchester.ac.uk \\ ${ }^{4}$ School of Computing, University of Portsmouth, UK \\ elisavet.andrikopoulou@port.ac.uk
}

\begin{abstract}
Dementia is estimated to affect 50 million people worldwide [1]. A significant proportion of residents in residential homes are people with moderate to severe dementia [2, 3]. Apathy amongst them is a major issue [3-5]. Tovertafel is an interactive table that was designed to reduce apathy and to facilitate play for people with moderate to severe dementia [6].

This mixed methods study has three aims; firstly to explore the Tovertafels' impact upon the wellbeing of people with moderate to severe dementia in a residential care home from the professional carers' perspective; secondly to explore the impact of Tovertafel on the wellbeing of these carers; and thirdly to explore whether Tovertafel has any impact on the quality and quantity of visits by the family of the residents. Semi-structured interviews were conducted with 12 carers and The Work Related Quality of Life Scale (WRQoL) [7] was used to explore carers' perspective of the extent to which Tovertafel improved their own wellbeing and the quality of their working life.

Some key findings indicate that visiting families interacted more with their loved-one when they are using the Tovertafel. Residents do use Tovertafel when it is switched on, but many needed to be initially prompted by staff. Tovertafel did have a positive impact upon residents' mood during the time it was used and a short time after. Tovertafel also had an impact on improving interaction between carers and residents when it was on. Tovertafel's most successful games are reported as being the bubbles and puzzles, and carers also stressed the importance of identifying an appropriate location for the Tovertafel, to enable optimum usage.
\end{abstract}

Keywords: Dementia, Wellbeing, Apathy, Mood, Interaction 


\section{$1 \quad$ Introduction}

Dementia is an umbrella term for a range of progressive conditions that affect the brain. The most common symptoms of dementia, which tends to develop gradually over time, are memory loss, mood changes, difficulty with reasoning, and problems with communication [8]. The number of people with dementia is increasing at a rapid rate, and it is estimated to affect 50 million people worldwide [1]. In the next five years, the number of people with dementia in the UK is expected to reach 1 million $[1,2]$. For those with dementia aged over 60 years, 55\% have mild dementia, 32\% have moderate dementia, and $12 \%$ have severe dementia [2].

A significant proportion of residents in residential and nursing homes are people living with moderate to severe dementia [2,3]. Apathy amongst these residents is a major issue [3-5] and is seen as the most common behavioral change experienced by people living with dementia [6]. Research indicates that $90 \%$ of nursing home residents with dementia experience apathy, which negatively influences their physical, cognitive, and emotional wellbeing [6,9]. These findings are worrisome, as the absence of physical activity correlates with the decline of physical health as well as cognitive capacities $[6,10]$.

Tovertafel (TT) is an interactive table that was designed to stimulate nursing home residents living with moderate to severe dementia with the aim of reducing feelings of apathy [6]. Research suggests that by enabling playful and stimulating activities, apathy can be reduced $[8,11]$. The research presented in this paper aimed to explore the potential for TT to improve the wellbeing of people living with moderate to severe dementia. It also explored any impact TT has upon the wellbeing of professional carers working within the residential care homes, as well as potential effect upon the quality or quantity of visits from families of the residents.

This study evaluates TT's impact on wellbeing from a professional carer's perspective in a longitudinal mixed-methods study. Qualitative and quantitative data were generated by conducting both interviews and questionnaires. It is anticipated that the output from this exploratory research will provide increased confidence in the effectiveness of TT to improve the wellbeing of specified target groups and may increase acceptance of the system.

\subsection{Aims and Objectives}

The research aims to explore whether the TT has the potential to improve the wellbeing of people within three user groups. Firstly, people with moderate to severe dementia residing in residential homes. Secondly, the wellbeing of professional carers, termed as staff, working within the residential care homes. Thirdly, any impact on the quality and quantity of visits from the resident's family.

The results of this research aim to show an improvement in wellbeing for both residents and staff when a TT is in use. The three objectives of this research include:

1. To explore the impact of TT on the wellbeing of people living with moderate to severe dementia in a residential care home from the staff's perspective. 
2. To explore the impact of TT on the wellbeing of staff in a residential care home which caters for people living with moderate to severe dementia.

3. To explore the quality and quantity of visits by the family of those who live in the residential care home for people with moderate to severe dementia from the staff's perspective.

\section{$2 \quad$ Method}

\subsection{Design and Procedure}

Based on the aims of this study, we conducted a longitudinal mixed-methods approach using qualitative and quantitative methods [13]. In this study, the quantitative and qualitative methods provide breadth and depth to understand the use of TT in promoting wellbeing in people living with moderate to severe dementia and their professional carers. The participants for this study are carers working at a residential home for people living with moderate to severe dementia in the UK. The qualitative and quantitative data were gathered from the same population. We concurrently surveyed and interviewed professional carers of people living with dementia. This included drawing their opinions on the impact upon wellbeing when TT was not in use and when in use. For this study the people living with dementia are referred to as "residents".

\section{$2.2 \quad$ Measures}

The interviews were conducted face-to-face and audio-recorded. Professional carers were asked questions on their own wellbeing, the wellbeing of the residents under their care, and their perspective on the quality and quantity of family visits. These qualitative semi-structured open questions were informed by Qualidem [14], a quality of life observation instrument rated by professional caregivers of persons with mild to very severe dementia living in residential settings. Since this is an exploratory study, we seek to explore the views of professional carers on how they perceive the wellbeing of people living with moderate to severe dementia. Professional carers were asked to provide their opinion on residents' wellbeing retrospectively and currently. This is in relation to a period of TT being turned off for one week and after a week of it being turned on.

The Work Related Quality of Life (WRQoL) scale was used in the current study to measure six factors [7] (as shown in Table 1). This scale was developed for health care workers in England to assess the quality of their working life [15, 16]. The WRQoL scale has robust psychometrics, good reliability and validity when tested with healthcare workers [7]. The WRQoL scale contains 24 items each evaluated on a 5 -point Likert scale $(1=$ strongly disagree to $5=$ strongly agree $)$ and produces six subscales which link to the Quality of Working Life [17]. Professional carers were asked to complete the survey after one week of TT being turned off and then again after the TT had been switched on for one week. 
Table 1. The six subscales of the WRQoL scale

\begin{tabular}{|c|c|c|c|}
\hline Subscale & Name & Abbreviation & Measure of: \\
\hline 1 & $\begin{array}{c}\text { Job and career } \\
\text { satisfaction }\end{array}$ & JCS & $\begin{array}{c}\text { Job and career } \\
\text { satisfaction }\end{array}$ \\
\hline 2 & $\begin{array}{c}\text { General Wellbe- } \\
\text { ing }\end{array}$ & GWB & $\begin{array}{c}\text { Everyday hap- } \\
\text { piness and satisfac- } \\
\text { tion }\end{array}$ \\
\hline 3 & Home-work & HWI & $\begin{array}{c}\text { Accommodating } \\
\text { family and work } \\
\text { commitments }\end{array}$ \\
\hline 4 & Stress at work & SAW & $\begin{array}{c}\text { Demands in the } \\
\text { workplace }\end{array}$ \\
\hline 5 & Control at work & CAW & $\begin{array}{c}\text { Level of control } \\
\text { carer feel they } \\
\text { have over deci- } \\
\text { sions at work }\end{array}$ \\
\hline 6 & $\begin{array}{c}\text { Working condi- } \\
\text { tions }\end{array}$ & WCS & $\begin{array}{c}\text { Phycal work- } \\
\text { ing environment }\end{array}$ \\
\hline
\end{tabular}

\subsection{Participants}

Participants were professional carers working at a residential home for people living with moderate to severe dementia in Hampshire, a county in the UK. All of the professional carers were given the option to take part in the study, via communication from the manager of the residential home. 12 of the staff voluntarily offered to participate. These participants were asked to complete the WRQoL scale after one week of the TT being turned off and again, after it had been turned on for a week. They were then interviewed on their perspective on whether TT has any impact on wellbeing, for both themselves and residents within the home. Participants were advised that they will be provided with feedback if required and they had the right to withdraw at any time during completing the questionnaire and interview. Once participants read the information sheet and signed the consent form, the questionnaire was completed and the researchers conducted the interviews. Confidentiality of participant's responses and the right to withdraw from the survey were outlined via instructions to the professional carers and in the provided information sheets.

\subsection{Analysis}

The analysis of qualitative and quantitative data included the following steps

1. Mixed methods data analysis involved analysing the quantitative and the qualitative data

2. Content analysis was used for qualitative analysis;

3. NVivo version 12 was used to support and document the qualitative analysis; 
4. Descriptive statistics were used to analyse the quantitative data in Microsoft Excel 2016

\section{$3 \quad$ Results}

\subsection{Qualitative Study}

Recent literature that informed the design of the qualitative study [3-8] indicated that there could be potential for TT in improving the wellbeing of people living with dementia, their carers, and family. Some of the themes derived from this literature as well as the Qualidem scale [14] include:

- Level of engagement

- Relationship of people living with dementia and their carers

- Mood change

- Restlessness

- Quantity and quality of family visits

Several other themes emerged from the qualitative thematic data analysis [18]. These emergent themes were categorised into: engagement using prompts; limited usage time; TT location; individuality; bubbles, popular games.

All of the 12 carers who agreed to participate in the study were interviewed.

\subsection{Engagement}

Participants reported positive changes in the engagement of residents when interacting with TT. This indicates that using the interactive table facilitated reduced apathy and helped people living with dementia to interact and concentrate more. This also implies that the provision of a TT system in the home creates the opportunity to keep the residents active and busy. Quotes from professional carers in relation to 'engagement' include:

P06 - "...I would say it changes when it is on because they seem more interested in what you are doing..."

P11 - "...It reduces boredom definitely..."

P12 - "...They have been happy when they play with it" and "...the one that uses it enjoy it..."

\subsection{Relationship between people with dementia and their carers}

The use of the TT table helped facilitate a positive relationship between people living with dementia and their carers. Some participants stated that the residents often want to discuss their experience in relation to interacting with the table, after using it. This then helped to create the opportunity to have further discussion, and strengthen the relationship between the carers and the residents. This is evident in some of the comments from the participants. 
P07 - "...It is better when it is switched on because you interact with them more..."

P06 - "...They socialise with you a bit better..."

P09 - "...They talk to you about it especially about the puzzle..."

Participants reported that some TT activities and games helped to improve the communication between them and the residents. With these activities, the residents seemed happier, laughed more, and the carers seemed more likely to interact with them. Some of the quotes from the participants include:

P07 - "...The bubble one helps, and the ball one is more enjoyable..."

P09 - "...They talk to you about it especially about the puzzles..."

Interestingly some expressed that the use of TT also facilitates improved interaction for them as carers and subsequent positive effect on the people they are caring for. One comment was:

P05 - "...you are more interactive with the service user when it is on..."

\subsection{Mood change}

The findings from this study suggest a positive effect of TT on the mood of the residents. They remained happy after they finished using TT. This, however, was shortlived as expected and in line with previous research on short attention span with people living with dementia [18]. It was commented that when residents take part in the TT activities, they interacted well with both other residents and staff, and appeared happy, however, this did not last all day. Comments from carers include:

P01 - "...They are happy for a short time..."

P03 - "...When we are taking part in it they interact, and they are happy and [Tovertafel] uplifts their mood in that moment, when they walk away, they are still in the uplifting happy mood, but it does not last all day..."

\subsection{Change in restlessness}

The carers expressed that the use of TT helped to keep the residents occupied. Consistent feedback indicates that the use of TT helped encourage the residents to be calmer. Residents did not appear to be anxious after sessions using TT. For example, one quote:

P02 - "...They are a bit calmer when the table is on. Not anxious..."

\subsection{Quality of family visit changes}

There is consistent feedback from all of the participants, which indicates that using TT has a positive effect on the quality of visits from the residents' families. Families interacted more with their loved ones when the TT is switched on. Some of the feedback includes:

P03 - "...when the table is on the families tend to go around it. And when it is not on they notice it was not on..." 
P11 - “...They sit with it and play games with it, and they interact with them more, rather than just come and sit there with a cup of tea..."

P03 - "...When the table is on the families, engage more and interact with their family members who are here. I think it is good because it builds up the interaction between families and they have something to do together instead just sitting here..."

Carers also reported that families appear to be happier when TT is switched.

P01 - "...when they visit and see the table on they seem happy..."

P04 - "...It builds up the interaction between families, and they have something to do together..."

Furthermore, families that visit with children would go over to play and interact with TT. This appeared to encourage residents to join their loved ones in engaging with the system.

P05 - "...It brings them together a little bit more..."

\subsection{Engagement using prompts}

Carers reported having to prompt residents to use TT, which subsequently helps keeps the residents engaged. Residents only seemed to be interested when their carers initiate the interactive table activities. This indicates that changes in the quality of engagement of their residents are based on prompts from carers. Comments from carers include:

P01- “...They do engage, no they kind of take-part in it but you have to prompt them to take part in it..."

P08 - "...we encourage them to sit and play..."

P01 - “...we prompt them saying let's play like this, let's do like this..."

P03 - "...you have to prompt them to take part..."

\subsection{TT location}

Some of the carers indicated that the TT would not only be used more but also be more effective if it was located in a specific location that was also regularly evaluated to ensure it facilitated optimum usage. In the case of the residential home featured in this study, the TT is located in the dining room. The feedback suggested:

P10 - "...I think it would be better if it were in a different location..."

P05 - "...it would be better if it were in a different location" and "...You have like the pool table in a pool table area, that sort of thing. Just in the dining area, people don't know but if it were sort of in a room where you have soft play or lights and things like that I think it would be used a lot more. Like a sensory room ..."

P06 - "...it should be in a different area because we use this as a dining area sometimes and you don't really associate that with playing. It should be in a sensory room or in one of the lounges..." 


\subsection{Consistency in switching the TT on}

Carers reported that residents are attracted to the interactive table when it was switched on. In addition, residents' families were also interested in using the table and seemed to notice when it is not in use. Observations from carers include:

P12 - "....I think more residents are attracted to it when it is on..."

P03 - "....when it is on they take part..."

P05 - "...I have to say when the table is on the families tend to go around it. And when it is not on, they notice it was not on..."

P11 - "...When it is switched on they engage..."

P04 - "...When the table first came, and we told them the table was on, they used it..."

\subsection{Limited usage time}

People with moderate to severe dementia find it hard to self-initiate and that their concentration can be poor $[18,19]$. This is consistent with our finding in this study that although TT seems to improve the residents' mood, the table is infrequently used by the residents without initiation from carers or loved ones, and sometimes for short durations. An explanation for limited usage time could be because people living with moderate to severe dementia have limited memory capacity and short concentration [19]. Comments include:

P08 - "....they will only play it for a very short time because their concentration is very short. They will do it for a little while...."

P09 - "...one minute they are with you and next minute in their mind they are somewhere else. And that's when they just get up and walk away..."

Furthermore, not all carers may be aware of the importance of encouraging residents to use it.

\subsection{Individuality}

Results from this study suggest that the extent of interaction using TT depends on the individual personality and general preferences of the person living with dementia. This finding resonates with previous research in the technology acceptance and personality domain [20]. A few professional carers shared:

P04 - "...some of them like the table more, and they do tap it and find it interesting. I think all depends on the resident individually...." and "...it is just a case of each individual liking or not to use the table..."

P06 - "...it depends on the person though, because you can have an actual conversation with some of them and they will enjoy it, whilst others they get frustrated and they walk away..." 


\subsection{Popular Games}

Carers reported that a few features of TT were more likely to be used and enjoyed than others. Puzzles and games seem to improve the engagement between the carers and residents. Feedback indicates that the most popular games are bubbles, ball and puzzles.

P11 - "...Some of the games are better than others, and some they enjoy more than others. The bubble one helps, and the ball one are more enjoyable..."

Puzzles also provided a good talking and engagement point, which needed to be initiated by the professional carers.

P09 - "...I think they engage more with the puzzle ones because you can do more with them..."

Furthermore, families of the residents also appeared to enjoy playing with the TT games, especially the one that displays quotes:

P05 - "...there are a lot of family members who come in who were with their clients and obviously sit around there and they remember the quote of them being children..."

\subsection{Professional carers wellbeing}

Although the majority of the professional carers did not notice any impact upon their own wellbeing when using TT, a few did highlight a positive mood change. For example:

P06 - “...We had a giggle playing the games, and this is a good thing. Keeps you thinking..."

This indicates that carers were more likely to interact and engage more with residents when TT is switched on. Feedback from carers included:

P07 - "...It is better when it is switched on because you interact with them more..."

P06 - "....they socialise with you a bit better...."

P05 - “...It is a little more engagement with people. You get together a bit more...."

\subsection{Results based on the WRQoL scale}

Whilst there were 12 carers who agreed to participate in the study, only 8 attempted to take part in the quantitative study using the WRQoL scale. Of the eight participants, five responses were not appropriate for the factor analytical technique as they had a least one missing value and were removed from the dataset. Whilst the numbers for the quantitative study are very low, the results were analysed for exploratory purposes.

As previously mentioned, the WRQoL scale can be used to measure the overall work-related quality of life, and this was adopted in this study [17]. All the responses across all six subscales were recorded on a five-point Likert-type scale. Responses to the WRQoL scale measured within this study shows the effect of the TT on the quality of life and wellbeing of the professional carer when it is switched on or off. Carers reported that their work-life balance and the extent to which they receive support from 
their employer regarding their home life increased when the TT is on. Their physical working environment is satisfactory with the provision of the TT at the residential home. The carers also reported that the level of control they have increased when the TT is on. Similarly, carers reported that there is a balance with the demand at workplace when the TT is switched off or on.

Table 2. Summary of changes to WRQoL Subscales when TT is switched off and on

\begin{tabular}{|l|l|l|}
\hline Subscale & TT Off & TT On \\
\hline GWB & $4.17(\mathrm{SD}=0.10, \mathrm{~N}=3)$ & $4.14(\mathrm{SD}=0.17, \mathrm{~N}=3)$ \\
\hline HWI & $4.33(\mathrm{SD}=0.31, \mathrm{~N}=3)$ & $4.38(\mathrm{SD}=0.32, \mathrm{~N}=3)$ \\
\hline WCS & $4.10(\mathrm{SD}=0.25, \mathrm{~N}=3)$ & $4.10(\mathrm{SD}=0.25, \mathrm{~N}=3)$ \\
\hline CAW & $3.76(\mathrm{SD}=0.24, \mathrm{~N}=3)$ & $3.90(\mathrm{SD}=0.21, \mathrm{~N}=3)$ \\
\hline SAW & $3.00(\mathrm{SD}=0.35, \mathrm{~N}=3)$ & $2.86(\mathrm{SD}=0.32, \mathrm{~N}=3)$ \\
\hline
\end{tabular}

The differences are generally minor, and 3 had almost identical scores during the time TT was off and when it was switched back on. The most noticeable difference between the times TT was on and off was in CAW and SAW factors. This might be explained in that carers who identified differences in these two factors, also mentioned the themes of mood changes and quality of family visit changes. There were no overall noticeable changes regarding the GWB and HWI factors. There are subtle differences in the rest of the factors JCS, WCS and the overall score, which are not considered substantial enough to provide a sound conclusion.

\section{Discussion}

The purpose of this study is to explore TT's impact upon the wellbeing of people living with moderate to severe dementia residing in residential homes and, furthermore, the wellbeing of professional carers working within these homes. In addition to the collated 'themes' that informed the structure of the interview, several other themes emerged from the study. Recommendations in relation to using TT to improve the wellbeing of people with dementia, and their professional carers will be discussed.

During the interviews, carers reported that TT has a positive impact on the level of engagement of the people living with dementia. This was seen to be a result of the varieties of play and activity available within the system. The analysis from the interviews consistently suggest that residents interact more with their loved-ones when they are sat around the TT. This finding supports the original research behind TT in that it facilitates engagement and improves play activity [6]. Findings from the study presented here, also suggest that residents would discuss their experience using TT afterwards and this subsequently creates the opportunity to engage in further discussion with carers, which helps in building on engagement and improving the carerresident relationship. Analysis of the interviews suggest that the families of the residents should be encouraged to use the table more often given the quality of interaction 
observed. Furthermore, the analysis indicates that families who visit with children would go over to play and interact with the interactive table. This encouraged residents to join their loved ones in engaging with the TT. Engaging in activities has a positive impact upon the psychological wellbeing of people with dementia [21, 22]. Similarly, literature indicates that involvement with activities is associated with reduced risk and slower progression of dementia [23].

The use of "prompts" seems to be an important factor given carers suggested that residents mostly engage when they are prompted to take part in TT activities. Research suggests that people with dementia are highly dependent on the use of prompts and cue facilitations by their carer or family [24-26]. This is explained by impaired cognitive ability, given the difficulty remembering appropriate sequence of actions [24-26]. Other research shows that reminders or prompts seem to be particularly effective for elderly patients, especially those with dementia [19, 20]. It is suggested that to enable optimum impact from TT, residents should be regularly prompted to interact with TT.

People living with dementia often have shorter attention spans [18]. The carers included within this study also mention this difficulty for the person living with dementia to maintain concentration for a significant period of time. This, coupled with the comments that the positive emotional effects of TT do not persist, suggests that the TT should be switched on regularly for short periods of time throughout the day. This may support the maintenance of positive emotions during the course of the whole day.

The location of TT also emerged as an important factor with comments from the interviews suggesting that having the system in a specially designated area could facilitate cues for the residents that it relates to a specific activity. In the residential home used in this study, the TT is located in the dining area. Residents sometimes confused activity time for tea/lunch time. Carers suggested moving the TT to either a sensory area that could potentially include further games and objects or to move it to a designated area. Increased use of activity spaces improves social interaction amongst residents $[24,25]$. It is suggested that TT should be situated in a specifically designed activity environment to encourage increased acceptance and usage.

Furthermore, there is some potential in encouraging carers to engage in the TT. It was identified that TT is used predominantly when a resident and a carer are using it together as a one-to-one form of interaction. Therefore, if the residential home encourages their professional carers to use TT, this subsequently could encourage residents to participate.

The results do show that TT had some impact upon carers' wellbeing. Using the WRQoL scale, carers did not report significant differences in their own wellbeing when the TT was switched on or off, however the sample size was very small. The interviews with a much larger sample size did indicate positive impact upon wellbeing during the interactions with residents. Caring for people with dementia can be stressful, and research suggests that carers have less time and opportunity to engage in wellbeing activities [26]. Carers may not have seen TT as an opportunity to engage in a wellbeing activity, nor might that TT have any positive impact upon their own wellbeing. Engaging in activities has been associated with an increase in positive mood, 
lowering the risk for chronic illness and increased stamina, which may improve carers' overall health and ability to perform their caregiving duties. Furthermore, research shows a correlation between caregivers' health and wellbeing with job satisfaction and retention $[27,28]$. It is therefore recommended that carers should be prompted to engage with TT due to the potential positive impact on their own wellbeing.

The findings from this study informed the development of a proposed TT influence model (Figure 1). This model suggests a two-layered approach with facilitators that could help encourage increased usage and may inform a subsequent improvement wellbeing of people with dementia and their professional carer. For example, to increase levels of engagement facilitated by the use of TT, there is a need to establish if users are prompted to use the system and it is in the right location. It is also important to ensure that the system is frequently switched on and the usage time is appropriate for the people living with dementia. This could also be applied with improving the wellbeing of the professional carers, the relationship of people with dementia, their mood, restlessness and the quality and quantity of family visits.

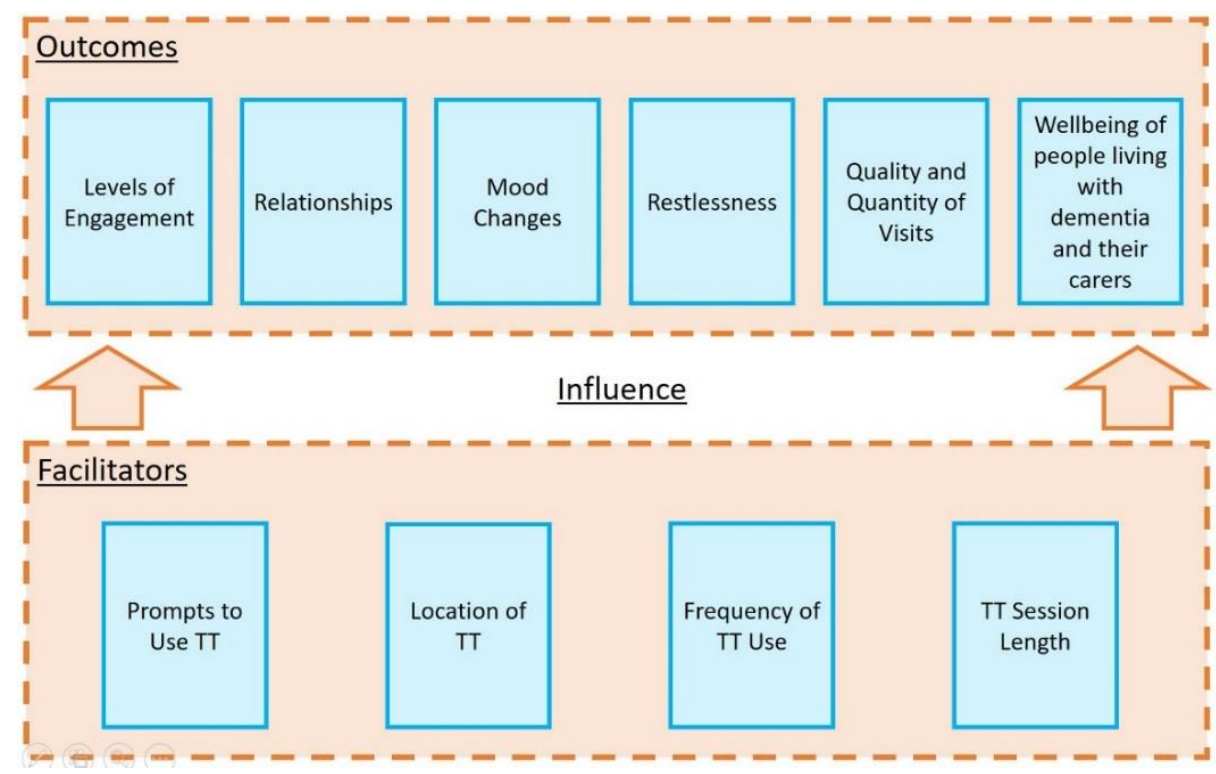

Fig. 1. Proposed TT Influence Model

\section{Conclusion}

This study contributes to the body of knowledge that TT has a positive effect upon the wellbeing of people living with moderate to severe dementia in residential homes, by improving their mood, reducing apathy and restlessness, as well as increasing levels 
of engagement. Furthermore, TT helped improve relationships between professional carers and these residents by facilitating playful activities. TT also facilitated increased quality of family visits when they are actively using the TT to interact with their loved ones. This research also indicates that TT can improve carers' overall health and ability to perform their caregiving duties, as well as increasing positive mood, lowering the risk for chronic illness and increasing stamina.

The results of this study were distilled into a potential TT Influence Model, which hopes to inform the facilitators and outcomes of effective use of TT. Future research should investigate whether this model contains all the relevant factors, and if it is effective at demonstrating how facilitators influence positive outcomes when using TT.

In this study a convenience sample of professional carers caring for people with moderate to severe dementia was utilised. The sample size and findings may not reflect professional carers of people with moderate to severe dementia in general, however, there are no specific rules for sample size in qualitative inquiry. Sample size depends on what you want to know, the purpose of the inquiry, what's at stake, what will be useful, what will have credibility, and what can be done with available resources [29]. The sample size of the qualitative study was deemed appropriate for an exploratory study. The quantitative study using the WRQoL scale was recognised as having a very small sample size however the results indicate that there is potential for carrying out further research to explore these findings further. As with all research of subjective experiences, there is a possibility of recall bias. Moreover, there is very little data that supports benefit to carers. This, however, is an exploratory study, which generated some positive findings and should therefore be viewed as a prelude to further research with an extended sample size.

In conclusion, there is a need to further explore the impact TT has on the professional carers and other staff of nursing homes in a larger study. Additional observational studies with both the professional carers, family and residents interacting with TT could help provide increased evidence on TT's impact upon wellbeing.

\section{Ethics}

This study was given a favourable opinion by the Faculty of Technology ethical review committee at the University of Portsmouth.

\section{$7 \quad$ Acknowledgements}

This research was supported by Shift8. 


\section{$8 \quad$ References}

1. Frankova, H. (2017). Dementia is a disease and diseases can be treated. Nursing And Residential Care, 19(8), 464-466.

2. Prince, M., Knapp, M., Guerchet, M., McCrone, P., Prina, M., Comas-Herrera, Adelaja, B. \& Rehill, A. (2017). Dementia UK: Update (2nd Ed) (Vol. 91). Retrieved from https://www.alzheimers.org.uk/sites/default/files/migrate/downloads/dementia_uk_update. pdf

3. Alzheimer Scotland. (2005). Activities: A guide for carers of people with dementia. Retrieved

from https://www.alzscot.org/assets/0002/9343/AlzScot_Activities_Booklet_WEB.pdf

4. Brodaty, H., \& Burns, K. (2012). Nonpharmacological Management of Apathy in Dementia: A Systematic Review. The American Journal of Geriatric Psychiatry, 20(7), 549-564. https://doi.org/10.1097/JGP.0B013E31822BE242

5. Holmén, K., Ericsson, K., \& Winblad, B. (2000). Social and emotional loneliness among non-demented and demented elderly people. Archives of Gerontology and Geriatrics, 31(3), 177-192. https://doi.org/10.1016/S0167-4943(00)00070-4

6. Anderiesen, H. (2017). Playful Design for Activation: Co-designing serious games for people with moderate to severe dementia to reduce apathy. https://doi.org/10.4233/UUID:EBEEF0FA-46FE-4947-86C1-C765A583770A

7. Van Laar, D., Edwards, J. A., \& Easton, S. (2007). The Work-Related Quality of Life scale for healthcare workers. Journal of Advanced Nursing, 60(3), 325-333. https://doi.org/10.1111/j.1365-2648.2007.04409.x

8. Dyer SM, Harrison SL, Laver K, Whitehead C, Crotty M. An overview of systematic reviews of pharmacological and non-pharmacological interventions for the treatment of behavioral and psychological symptoms of dementia. Int Psychogeriatrics [Internet]. 2017/11/16. 2018;30(3):295-309. Retrieved from: https://www.cambridge.org/core/article/an-overview-of-systematic-reviews-ofpharmacological-and-nonpharmacological-interventions-for-the-treatment-of-behavioraland-psychological-symptoms-of-dementia/DCA87B8BC78047977CB92427BF3F4FC3

9. Kolanowski, A. M., Litaker, M., \& Buettner, L. (2005). Efficacy of Theory-Based Activities for Behavioral Symptoms of Dementia. Nursing Research, 54(4). Retrieved from https://journals.lww.com/nursingresearchonline/Fulltext/2005/07000/Efficacy_of_Theory_ Based_Activities_for_Behavioral.3.aspx

10. Colcombe, S., \& Kramer, A. F. (2003). Fitness Effects on the Cognitive Function of Older Adults: A Meta-Analytic Study. Psychological Science, 14(2), 125-130. https://doi.org/10.1111/1467-9280.t01-1-01430

11. Blondell, S. J., Hammersley-Mather, R., \& Veerman, J. L. (2014). Does physical activity prevent cognitive decline and dementia?: A systematic review and meta-analysis of longitudinal studies. BMC Public Health, 14, 510. https://doi.org/10.1186/1471-2458-14-510

12. Heyn, P., Abreu, B. C., \& Ottenbacher, K. J. (2004). The effects of exercise training on elderly persons with cognitive impairment and dementia: A meta-analysis. Archives of Physical Medicine and Rehabilitation, 85(10), 1694-1704. https://doi.org/10.1016/J.APMR.2004.03.019

13. Creswell, J. W., \& Plano Clark, V. L. (2017). Designing and conducting mixed methods research. Los Angeles: SAGE. Retrieved from http://search.ebscohost.com/login.aspx?direct=true \&db=cat01619a\&AN=up.1260349\&site $=$ eds-live 
14. Ettema TP, Dröes R-M, de Lange J, Mellenbergh GJ, Ribbe MW. QUALIDEM: development and evaluation of a dementia specific quality of life instrument-validation. Int $\mathbf{J}$ Geriatr Psychiatry [Internet]. 2007 May;22(5):424-30. Available from: http://doi.wiley.com/10.1002/gps.1692

15. Danna, K., \& Griffin, R. W. (1999). Health and Well-Being in the Workplace: A Review and Synthesis of the Literature. Journal of Management, 25(3), 357-384. https://doi.org/10.1177/014920639902500305

16. Zeng, X., Chaiear, N., Klainin, P., Khiewyoo, J., Koh, D., Hien, P. W. H., \& Lee, S. Y. (2011). Work-related quality of life scale among Singaporean nurses. Asian Biomedicine, 5(4), 467-474.

17. Easton, S., \& Laar, D. van. (2018). User Manual for the Work-Related Quality of Life (WRQoL) scale. [electronic resource]: A Measure of Quality of Working Life. Portsmouth: University of Portsmouth, Quality of Working Life. Retrieved from http://search.ebscohost.com/login.aspx?direct=true \&db=cat01619a\&AN=up. $1276003 \&$ site =eds-live

18. Braun, V., \& Clarke, V. (2006). Using thematic analysis in psychology. Qualitative Research in Psychology, 3(2), 77-101. Retrieved from http://eprints.uwe.ac.uk/11735

19. Lyketsos CG, Steinberg M, Tschanz JT, Norton MC, Steffens DC, Breitner JCS. Mental and Behavioral Disturbances in Dementia: Findings From the Cache County Study on Memory in Aging. Am J Psychiatry [Internet]. 2000 May 1;157(5):708-14. Available from: https://ajp.psychiatryonline.org/doi/abs/10.1176/appi.ajp.157.5.708

20. Svendsen GB, Johnsen JAK, Almås-Sørensen L, Vitters $\varnothing$ J. Personality and technology acceptance: The influence of personality factors on the core constructs of the Technology Acceptance Model. Behav Inf Technol. 2013;32(4):323-34.

21. Harmer, B. J., \& Orrell, M. (2008). What is meaningful activity for people with dementia living in care homes? A comparison of the views of older people with dementia, staff and family carers. Aging and Mental health, 12(5), 548-558.

22. Marshall, M. J., \& Hutchinson, S. A. (2001). A critique of research on the use of activities with persons with Alzheimer's disease: A systematic literature review. Journal of Advanced Nursing, 35(4), 488-496.

23. Saczynski, J. S., Pfeifer, L. A., Masaki, K., Korf, E. S., Laurin, D., White, L., \& Launer, L. J. (2006). The effect of social engagement on incident dementia: the Honolulu-Asia Aging Study. American Journal of Epidemiology, 163(5), 433-440.

24. Kovach, C., Weisman, G., Chaudhury, H., \& Calkins, M. (1997). Impacts of a therapeutic environment for dementia care. American Journal of Alzheimer's disease, 12(3), 99-110.

25. Volicer, L., Simard, J., Pupa, J. H., Medrek, R., \& Riordan, M. E. (2006). Effects of continuous activity programming on behavioral symptoms of dementia. Journal of the American Medical Directors Association, 7(7), 426-431.

26. Orgeta, V., \& Miranda-Castillo, C. (2014). Does physical activity reduce burden in carers of people with dementia? A literature review. International journal of geriatric psychiatry, 29(8), 771-783.

27. Perry L., Gallagher R., Duffield C., Sibbritt D., Bichel-Findlay J. \& Nicholls R. (2016) Journal of Nursing Management 24, 1088-1097. Does nurses' health affect their intention to remain in their current position?

28. Duggleby, W. , Cooper, D. and Penz, K. (2009), Hope, self-efficacy, spiritual well-being and job satisfaction. Journal of Advanced Nursing, 65: 2376-2385. doi:10.1111/j.13652648.2009.05094.x 
29. Marshall, B., Cardon, P., Poddar, A., \& Fontenot, R. (2013). Does sample size matter in qualitative research?: A review of qualitative interviews in IS research. Journal of Computer Information Systems, 54(1), 11-22. 